https://doi.org/10.30910/turkjans.448354

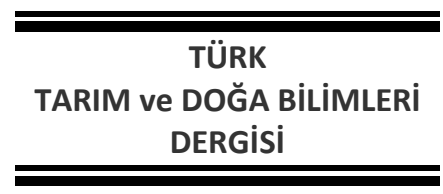

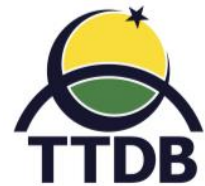

www.dergipark.gov.tr/turkjans

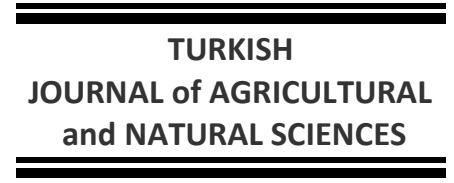

Araştırma Makalesi

\title{
Çanakkale ili Çilek Alanlarında Yeni Bir Zararlı Drosophila suzukii (Matsumura) (Diptera: Drosophilidae)'nin Yayılış Alanları ve Bulaşıklılığı
}

\author{
Levent EFIL* \\ *ÇOMU Ziraat Fakültesi, Bitki Koruma Bölümü, 17100 Çanakkale \\ *Sorumlu yazar: efil46@hotmail.com
}

Geliş Tarihi: 29.05.2018

Düzeltme Geliş Tarihi: 06.06.2018

Kabul Tarihi: 21.06.2018

\begin{abstract}
Özet
Çalışmada, Çanakkale ili çilek üretim alanlarında 2017 yılında Drosophila suzukii'nin yayılış alanları ve bulaşıklık oranı belirlenmiştir. Bu amaçla, çilek üretiminin yoğun olarak yapıldığı Ayvacık ve Yenice ilçelerinde sörvey çalışmaları yürütülmüştür. Çalışma sonucunda Çanakkale ilindeki çilek üretim alanlarında ilk defa $D$. suzukii belirlenmiştir. Sörvey yapılan tüm alanların tamamının zararlı ile bulaşık olduğu tespit edilmiştir. Çilek üretiminin yapıldığı alanların birbirinden tamamen farklı rakımlara ve özelliğe sahip olması $D$. suzukii'nin yükseklik farkı gözetmeksizin zarar yapabileceğini göstermiştir. Zararlının olgunlaşan meyvelere yumurta bırakması ve larvaların direkt olarak meyvelere zarar vermesi zararını arttırmaktadır. Çilek hasadının geciktirilmemesi ve zarar görmüş meyvelerin toplanıp imha edilmesi ile zarar oranının azaltılabileceği görülmüştür. Bölgede yetiştirilen çilekler iç piyasada tüketildiği için bu zararının diğer bölgelere bulaşma kaynağı oluşturmayacağı kanısına varılmıştır. Sonuç olarak Çanakkale ili çilek üretim alanlarının zararlı ile bulaşık olması ve istilacı bir tür olması nedeniyle daha ayrıntılı çalışmaların yapılması gerekmektedir.
\end{abstract}

Anahtar kelimeler: Çanakkale, çilek, bulaşıklık, Drosophila suzukii.

\section{Infestation, Distribution Areas of New pest Drosophila suzukii (Matsumura) (Diptera: Drosophilidae) on Strawberries in Çanakkale Provinces}

\begin{abstract}
Infection and distribution areas of Drosophila suzukii were determined in Çanakkale province in strawberry growing areas in 2017. The studies were carried out in Ayvacik and Yenice districts where strawberry farming was intensively cultivated. At the end of the study, D. Suzukii was determined first time in strawberry fields in Çanakkale province. It has been determined that all areas surveyed are infected with the pest. The fact that the places where strawberry cultivation is made have altogether different altitudes and features, it has shown that $D$. Suzukii could damage regardless of altitude difference. Laying its eggs fruits and damaging of larvae directly to fruits increase the damage. It has been seen that no delaying the strawberry harvest and collecting and destroying the damaged fruit can reduce the damage rate. Since the strawberry grown in the region is consumed in the inner market, it has come to the conclusion that the pest does not constitute a infection source to the other regions. As a result, more detailed studies are needed in Çanakkale province because the strawberry cultivation areas are contaminated with pest species that is an invasive. In this study, it was determined that the avoidance and preferences of two different earthworm species towards different organic materials mixed with soil were different from those of the E. fetida earthworm species with respect to composted organic material of O. transpadanus earthworm species.
\end{abstract}

Key words: Çanakkale, strawberry, infestation, Drosophila suzukii. 


\section{Giriş}

Çilek, Türkiye'de hem yurt içinde tüketilen hem de ihraç edilen önemli bir üzümsü meyvedir. Çanakkale ilinde yaklaşık olarak 6 bin da alanda çilek üretimi yapılmakta ve tamamına yakını iç piyasada tüketilmektedir (Anonim, 2017). Çanakkale'de çilek üretimi geniş bir zaman diliminde yapılırken, sahile yakın kesimlerde mayıs ayında başlayan hasad kasım ayına kadar sürmekte, Kaz dağlarına yakın bölgelerde yapılan çilek üretimi ise uzun sürmekle birlikte sahil kesimlere göre geç başlamakta ve erken bitmektedir. Çilek üretim sezonunun uzun olması ve farklı yükseltilerde çilek üretiminin yapılması zararlıların sorun oluşturması için farklı ortamlar sağlamaktadır. Bu sorunlardan bir tanesi de son yıllarda birçok ülkede yayılma gösteren, bulaştığı yerlerde meyve üretimini tehdit eden ve önemli bir karantina zararlısı olan kanadı noktalı sirke sineği Drosophila suzukii (Matsumara)'dir.

D. suzukii Asya kökenli istilacı bir türdür (Cini ve ark., 2012., Timmeren ve Isaacs, 2013). Avrupa'da ilk olarak İtalya'da çilek alanlarında belirlenmiş, daha sonra batı ülkeleri ve Amerika'yı istila etmiş, kısa sürede bu ülkelerin bir çok yerine bulaşmış ve meyve üretimini tehdit eder hale gelmiştir (Cini ve ark., 2012; Chabert ve ark., 2012; Stabelli ve ark., 2013). Son yıllarda Dünyadaki meyve üretim bölgelerinin çoğuna da bulaşmış durumdadır (Timer ve Isaacs, 2013). D. suzukii'nin varlığı son olarak Güney Amerika ve Kanada'da bildirilmiştir (Depra ve ark., 2014; Wilson, 2017). D. suzukii'nin Türkiye' deki varlığı ise ilk olarak Orhan ve ark. (2016) tarafından çilek bitkisinde belirlenmiştir.

D. suzukii bulaştığı ve yayıldığı alanlarda meyve üretiminde önemli azalmalara neden olmuştur (Walsh ve ark., 2011). illk bulaşmalar limanlara yakın bölgelerde olmuş ve diğer alanlara buralardan yayılmıştır. Asya'dan ithal edilen meyvelerin içerisinde yumurta veya larva halinde gelmiş, bulaştığı alanlardaki meyvelerde doğal rekabetçilerinin olmaması ve etkili doğal düşmanlarının bulunmaması gibi nedenlerle hızlı ve kolay bir şeklide yayılmışlardır. İklim şartlarına kolayca adapte olmaları, meyve ticareti ile kolayca taşınması yayılma hızı ve başarısını arttıran diğer etkenler olmuştur (Stabelli ve ark., 2013).

De Ros ve ark. (2013) D. suzukii'nin çilek meyvesinde önemli bir zararlı konumuna geldiğini ifade etmişlerdir (Zararlı Kaliforniya'da 2008 yılında çilek alanlarında belirlenmiş ve daha sonra Florida'daki çilek alanlarına yayılmıştır (Dean ve ark., 2013). Çilek meyvesi bu zararlıya karşı çok hassastır (Lee ve ark., 2011). Dişi bireyler hayatı boyunca 600 kadar yumurtayı olgunlaşan ve zarar görmemiş çilek meyvelerine tırtıklı ovipozitörleri sayesinde hasat öncesi kolayca bırakmaktadır (Sasaki ve Sato., 1995; Grassi ve ark., 2011; Calabari ve ark., 2012; Cini ve ark., 2012). Çilek meyvesi içerisine bırakılan yumurtalar burada açılmakta ve çıkan larvalar meyve ile beslenmektedirler. Amerika Birleşik Devletlerinde zararlının konukçusu olan bitki türlerinde bu zararlıdan dolayı meydana gelen ürün kaybının \%20 olduğu ve maddi kaybın ise 511.3 milyon dolar olduğu bildirilmektedir (Bolda ve ark., 2010). Avrupa ülkeleri için verim kayıpları Fransa'da \%80, İspanya'da \%100, İtalya'da ise \%30-40 arasında olduğu bildirilmektedir (Lee ve ark., 2012). D. suzukii'nin zararının gelecekte çilek endüstrisini olumsuz yönde etkileyebileceği bildirilmiştir (Keesey ve ark., 2015). D. suzukii, son yıllarda Dünya'daki birçok ülkenin meyve üretimini ve ticaretini olumsuz yönde etkileyebilecek düzeye gelmiştir. Farklı ülkelerde birçok araştırıcı tarafından zararlıyı tanıma ve çözüm üretebilme amaçlı çalışmalar yürütülmektedir. Çalışmada, Çanakkale tarımı için önem arz eden çilek üretim alanlarında D. suzukii'nin yayılış alanlarının ve bulaşıklık oranının belirlenmesi amaçlanmıştır.

\section{Materyal ve Yöntem}

Çalışma, Çanakkale ilinde çilek üretiminin yapıldığı Yenice ilçesine bağlı yedi köyde on dokuz, Ayvacık ilçesine bağı ıki köyde beş olmak üzere toplam yirmi dört çilek tarlasında 2017 yılı eylül ve ekim aylarında yürütülmüştür. Çilek alanlarına belirli aralıklarla gidilmiş ve çilek meyveleri toplanmıştır Her tarladan tesadüfen 50 adet gelişmesini tamamlamış ve olgunlaşmış çilek meyveleri toplanmıştır. Çilek meyvelerinin çürümüş olmamasına dikkat edilmiş ve dış görünüşünde zararlanma olmayan meyveler seçilmiştir. Toplanan çilek meyveleri üzeri etiketlenmiş kültür kaplarına alınmış (11 cm çap ve $17 \mathrm{~cm}$ boy) ve laboratuvara getirilmiştir. Laboratuvara getirilen meyveler şeffaf plastik kaplarda ( $5 \mathrm{~cm}$ çap ve $5 \mathrm{~cm}$ derinliğindeki alt kısmında kurutma kâğıdı bulunan) kültüre alınmış ve elde edilen ergin sinekler \%70'lik etil alkol içerisine alınarak teşhisi yaptırılmıştır.

\section{Bulgular ve Tartışma}

Çilek alanlarından toplanan çilek meyveleri kültüre alınmışlardır. Meyvelerde ilk olarak gözle yapılan kontrollerde toplanan örneklerin hiç birisinde larva gözlenmemiştir. Zaman geçtikçe bulaşık meyvelerde bulaşık olmayan meyvelere göre yumuşamalar, bozulmalar başlamış ve larvalar belirlenmiştir (Şekil 1). Daha sonra bu meyveler çürümeye başlamıştır (Şekil 2). Gelişmesini tamamlayan larvalar meyvenin dış kısmında pupa olmuşlardır. Zararlının bulaştığı ve larvasının elde edildiği meyvelerin hepsinden bir veya daha fazla larva ve sonuçta pupa elde edilmiştir. Cini ve ark. (2012) yürüttükleri bir çalışmada $D$. suzukii'nin keskin ve tırtıklı ovipozitörü sayesinde yumurtalarını 
çilek meyvesi içerisine bıraktıklarını, yumurtadan çıkan larvaların meyve içinde beslendiklerini ve burada gelişmelerini tamamladıklarını belirtmişlerdir. Ayrıca aynı araştırıcılar D. suzukii'nin her bir meyveye 1-3 adet yumurta bıraktığını ve

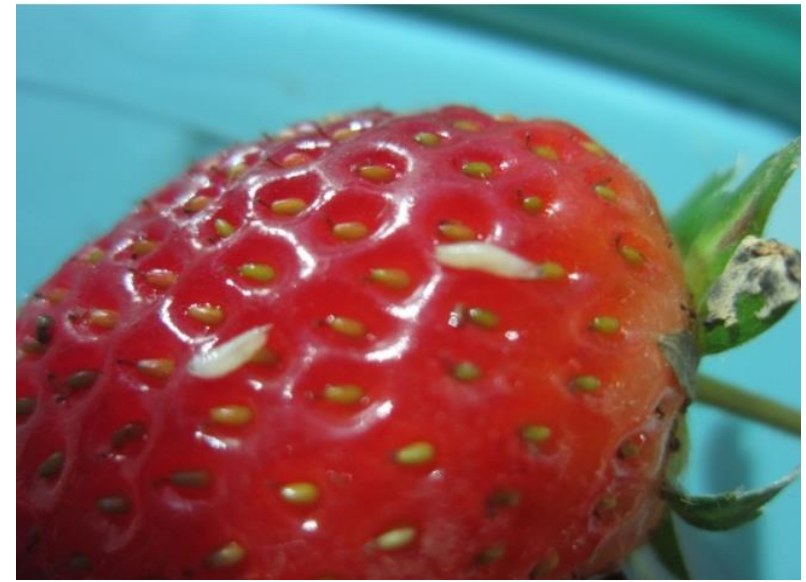

Şekil 1. Çilek meyvesi üzerinde Drosophila suzukii larvaları.

Yenice ve Ayvacık ilçelerinde dokuz köyde toplam yirmi dört tarlada örnekleme me yapılan tarlaların tamamının D. suzukii ile bulaşık olduğu belirlenmiştir (Çizelge 1). Ayvacık ilçesindeki Tuzla ve Babadere köylerindeki çilek alanları deniz kıyısında olmasına rağmen diğer çilek tarlalarının tamamı dağlık ve ormanlık alanların içerisindeki köylerde yer almaktadır Bu iki ilçedeki çilek tarlaları arasında büyük yükselti farklılığı bulunmaktadır. Buna göre $D$. suzukii'nin yükseklik ve çevre şartlarındaki farklılığa rağmen tüm çilek üretim alanlarına yayılabildiği belirlenmiştir. Yapılan çalışmalarda, D. suzukii'nin Avrupa'da 27 metre yükseklikten 1550 metre yüksekliğe kadar olan alanlara yayıldıkları (Calabria ve ark., 2012), iklim koşullarının sınırlayıcı bir etken olmadığı (Depra ve ark., 2014) ve farklı yerlere kolayca adapte olabildikleri bildirilmektedir (Calabria ve ark., 2012). D. suzukii bulaştığı alanlarda biyolojik çeşitliliği ve ekolojiyi tehdit edebilmekte (Stabelli ve ark., 2013) ve bu tür istilacı türler doğal hayata zarar verebilmektedir (Cini ve ark., 2014). Çanakkale ilinde çilek üretiminin yapıldığı alanlar yoğun tarımın yapılmadığı ve ilaçlama sayısının az olduğu alanlardır. Özellikle Yenice ilçesindeki çilek üretim alanları Kaz dağları içerisinde olup, bu alanlarda $D$. suzukii'nin doğal çevreye zarar verebilmesi olasıdır. Bölgede çilek alanlarında ilk defa belirlenen $D$. suzukii'nin kışlama durumu, ilk erginlerin görüldüğü tarih, konukçuları ve davranışlarının belirlenmesi gerekmektedir. Kışlaktan çıkan ilk erginlere karşı kitlesel yakalama metotları araştırılma ve etkili olabilecek doğal düşmanları belirlenmelidir. Nitekim yapılan bir çalışmada etkili doğal düşmanların $D$. suzukii'nin popülasyonlarının pupaların meyve içinde veya dışında oluştuklarını bildirmişlerdir. Yürütülen başka bir çalışmada $D$. suzukii'nin yumurtalarını zarar görmemiş meyveler içerisine bıraktığı belirtilmiştir (Sasaki ve Sato 1995; Kesey ve ark., 2015).

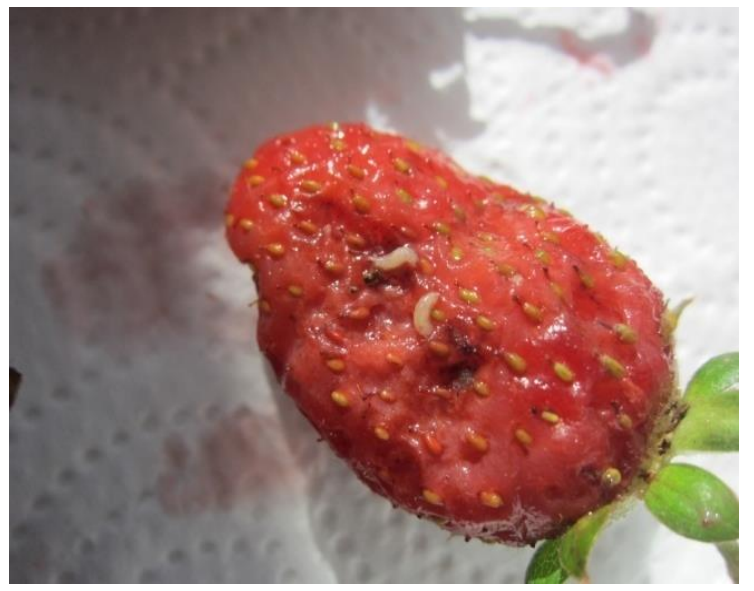

azaltılmasında yardımcı olabileceği belirtilmiştir (Gabarra ve ark., 2015).

\section{Sonuç ve Öneriler}

Çilek, Çanakkale tarımı için önemli bir üründür. Hasat süresinin uzun olması ve çok geç dönemlerde (ekim-kasım aylarında) de hasat yapılabilmesi üründen alınan geliri arttırmaktadır. Bununla birlikte $D$. suzukii için çok uygun bir konukçu olan çilek meyvesinin uzun süre ortamda bulunması zararlının popülasyonunun artması için etkili faktörlerden bir tanesidir. Bulaşık olan meyvelerin üreticiler tarafından tarlada bırakılması sonucunda çilek meyvelerinin yaydıkları kokular sayesinde çilek alanlarına daha çok ergin sinekleri çekmektedir. Bu meyvelere diğer türler de yumurta bırakabilmektedir. Bulaşık olan meyvelerin tarla içerisinde bırakılmayıp, imha edilmesinin zararın azaltılmasında etkili olabileceği görülmüştür. Survey çalışmaları esnasında D. suzukii'nin olgunlaşan meyvelere yumurta bıraktıkları gözlenmiştir. Üreticilerin yaptıkları hatalardan bir tanesi de olgunlaşan meyveleri hasat etmeyip, diğer meyvelerinde hasada gelmesini beklemesidir. Bu nedenle de zararlının yumurta bırakabileceği ortam artmaktadır. Bunu önlemek için olgunlaşan meyvelerin hemen hasat edilmesi gerekmektedir. Bununla birlikte üretilen çileklerin tamamına yakın bir kısmının iç piyasada tüketilmesinin zararlının diğer bölgelere bulaşma riskini azalttı̆̆ görülmüştür. 


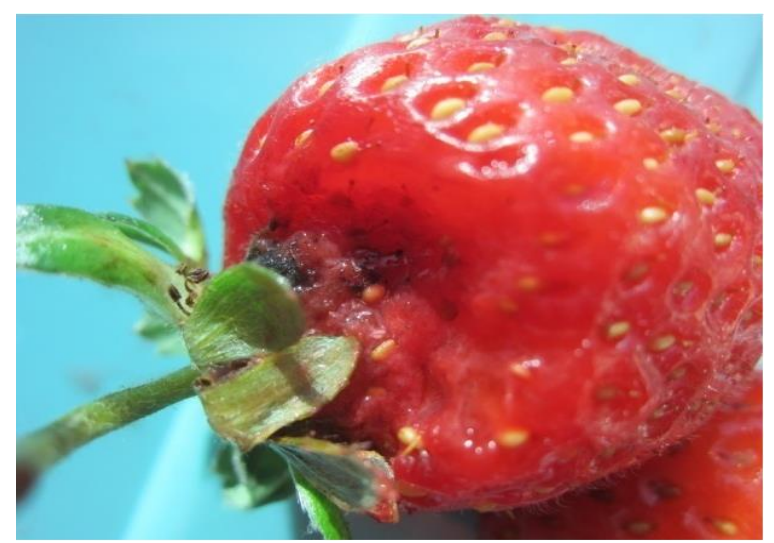

Şekil 2. Çilek meyvesinde Drosophila suzukii zararı.

Çizelge 1. Çanakkale ili Yenice ve Ayvacık ilçelerindeki çilek alanlarında Drosophila suzukii'nin yayılışı ve bulaşıklık oranı (\%).

\begin{tabular}{|c|c|c|c|}
\hline İlçe & Köy & $\begin{array}{l}\text { Tarla } \\
\text { sayısı }\end{array}$ & $\begin{array}{c}\text { Bulaşıklılık Oranı } \\
(\%)\end{array}$ \\
\hline \multirow{8}{*}{ 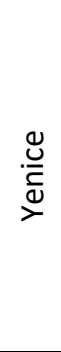 } & Çınarcık & 3 & 100 \\
\hline & Hamdibey & 3 & 100 \\
\hline & Kalkım & 3 & 100 \\
\hline & Akçakoyun & 3 & 100 \\
\hline & Örencik & 3 & 100 \\
\hline & Yukarıçavuş & 2 & 100 \\
\hline & Aşağıçavuş & 2 & 100 \\
\hline & Toplam & 19 & \\
\hline \multirow{3}{*}{ 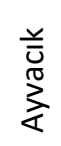 } & Tuzla & 2 & 100 \\
\hline & Babadere & 3 & 100 \\
\hline & Toplam & 5 & 100 \\
\hline \multicolumn{2}{|c|}{ Genel Toplam } & 24 & 100 \\
\hline
\end{tabular}

\section{Teşekkür}

D. suzuki'nin teşhislerini yapan Dr. Banu Şebnem ÖNDER'e teşekkür ederim.

\section{Kaynaklar}

Anonim, 2017. Çanakkale il Gıda Tarım ve Hayvancılık Müdürlüğü Verileri.

Bolda, M.P., Goodhue, R.E., Zalom, F.G. 2010. Spotted wing drosophila: potential economic impact of a newly established pest. Giannini Foundation Agric. Econ, 5-8.

Calabria, G., Ma'ca, J., Ba“chli, G., Serra, L., Pascual, M. 2012. First records of the potential pest species Drosophila suzukii (Diptera: Drosophilidae) in Europe. J Appl Entomology 136:139-147.

Chabert, S., Allemand, R., Poyet, M., Eslin, P., Gibert, P. 2012. Ability of European parasitoids (Hymenoptera) to control a new invasive Asiatic pest, Drosophila suzukii. Biological Control 63: 40-47.
Cini, A., loriatti, C., Anfora, G. 2012. A review of the invasion of Drosophila suzukii in Europe anda draft research agenda for integrated pest management. Bulletin of Insectology 65(1): 149-160.

Cini, A., Anfora, G., Escudero-Colomar, L.A., Grassi, A., Santosuosso, U., Seljak, G., Papini, A. 2014. Tracking the invasion of the alien fruit pest Drosophila suzukii in Europe J Pest Science 87: 559-566.

Dean, D., Price, J.F., Steck, G., Nagle, C.A. 2013. Development and Impact of the Spotted WingDrosophila, Drosophila suzukii, in Florida Strawberries. International Journal of Fruit Science 13: 67-75.

Depra', M., Poppe, J.L., Schmitz, H.J., Toni, D.C. De., Valente, V.L.S. 2014. The first records of the invasive pest Drosophila suzukii in the South American continent. J. Pest Science 87: 379383

De Ros, G., Anfora, G., Grassi, A., loriatti, C. 2013. The potential economic impact of Drosophila suzukii on small fruits production in Trentino (Italy). Integrated protection of fruit crops IOBC-WPRS Bulletin 91: 317-321.

Gabarra, R., Riudavets, J., Rodríguez, G.A., PujadeVillar, J., Arno, J. 2015. Prospects for the biological control of Drosophila suzukii. BioControl 60: 331-339.

Grassi, A., Giongo, L., Palmieri, L. 2011. Drosophila (Sophophora) suzukii (Matsumura), new pest of soft fruitsin Trentino (North-Italy) and in Europe. Integrated Plant Protection in Soft Fruits IOBC/wprs Bulletin 70: 121-128.

Keesey, I.W., Knaden, M., Hansson, B.S. 2015. Olfactory specialization in Drosophila suzukii supports an ecological shift in host preference from rotten to fresh fruit. J. Chem Ecol 41: 121-128.

Lee, J.C., Bruck, D.J., Curry, H., Edwards, D., Haviland, D.R., Vansteenwyck, R.A., Youngey, B.M. 2011. The susceptibility of small fruit and cherries to the spotted wing Drosophila, Drosophila suzukii. Pest Management Science 67: 1358-1367.

Lee, J.C., Burrack, H.J., Barrantes, L.D., Beers, E.H., Dreves, A.J., Hamby, K.A., Haviland, D.R., Isaacs, R., Richardson, T.A., Shearer, P.W., Stanley, C.A., Walsh, D.B., Walton, V.M., Zalom, F.G., Bruck D. J. 2012. Evaluation of Monitoring Traps for Drosophila suzukii (Diptera: Drosophilidae) in North America. Journal of Economic Entomology, 105(4): 1350-1357.

Orhan, A., Aslantaş, R., Önder, B.S., Tozlu, G. 2016. First record of the invasive vinegard fly Drosophila suzukii (Matsumara) (Diptera: 
Drosophilidae) from eastern Turkey. Türk J. Zool, 40: 290-293.

Sasaki, M., Sato, R. 1995. Bionomics of the cherry drosophila, Drosophila suzukii Matsumura (Diptera: Drosophilidae) in Fukushima prefecture (Japan). Annual Report of the Society of Plant Protection of North Japan 46: 164-172.

Stabelli, O., Blaxter, M., Anfora, G. 2013. Quick guide: Drosophila suzukii. Curr Biol., 7 January 2013, 23(1): R8-R9.

Timmeren, S.V. Isaacs, R. 2013. Control of spotted wing drosophila, Drosophila suzukii, by specificinsecticides and by conventional and organic crop protection programs. Crop Protection 54: 126-133.

Walsh, D.B., Bolda, M.P., Goodhow, R.E., Dreves, A.J., Lee, J., Bruck, D.V., Walton, M., O'Neal, S.D., Zalom, F.G. 2011. Drosophila suzukii (Diptera: Drosophilidae): invasive pest of ripening soft fruit expanding its geographic range and damage potential. J Integraten Pest Management 106: 289-295.

Wilson, C. 2017. A review of the monitoring and management of spotted-wing drosophıla (Drosophıla suzukii) in lowbush blueberrıes. Proceedings of the Nova Scotian Institute of Science, 49(1): 145-156.vineyards with different inputs. Applied Soil Ecology. 10: 137-150. 